\title{
Laparoscopic Management of Cesarean Section Scar Ectopic Pregnancy
}

\author{
${ }^{1}$ Meenu Agarwal, ${ }^{2}$ Sandhya Meshram
}

\begin{abstract}
Cesarean scar pregnancy (CSP) is defined as an implantation of pregnancy in a fibrous tissue scar of a previous cesarean section. It is considered as one of the rarest forms of ectopic pregnancy and can be life threatening. The incidence of CSP is steadily rising in view of increasing cesarean section rates. A very high index of clinical suspicion is required for the diagnosis and further management. Through this case report, we demonstrate the laparoscopic management of a previous failed methotrexate (MTX) therapy in a CSP.
\end{abstract}

Keywords: Caesarean scar ectopic, Ectopic pregnancy, Laparoscopy.

How to cite this article: Agarwal M, Meshram S. Laparoscopic Management of Cesarean Section Scar Ectopic Pregnancy. Int J Gynecol Endsc 2018;2(1):38-41.

Source of support: Nil

Conflict of interest: None

\section{INTRODUCTION}

Cesarean scar pregnancy is defined as an implantation of pregnancy in a fibrous tissue scar of a previous cesarean section. ${ }^{1}$ The first case of CSP was reported by Larsen and Solomon in 1978. ${ }^{2}$ Jurkovic et $\mathrm{al}^{3}$ and Seow et $\mathrm{al}^{4}$ have estimated a prevalence of CSP in their local population of women attending the early pregnancy assessment unit as 1:1,800 and 1:2,216 respectively. ${ }^{1}$ The median gestation at diagnosis was 6.8 weeks (5.5-11.5 weeks). ${ }^{3}$ The time interval between the last cesarean section and the CSP was 6 months to 12 years. ${ }^{2}$

Cesarean scar pregnancy progressing to 28 weeks of gestation has been described which led to a viable birth but a cesarean hysterectomy had to be performed in view of placenta percreta. ${ }^{6}$ Its genesis involves implantation into the myometrium through a microscopic tract or sometimes a dehiscence in the previous uterine

\footnotetext{
${ }^{1}$ National Director-Clinical Board, ${ }^{2}$ Unit Head

${ }^{1}$ Department of Endoscopy and ART, Morpheus IVF, Pune Maharashtra, India

${ }^{2}$ Department of Endoscopy and ART, Morpheus Bliss Fertility Centre, Pune, Maharashtra, India

Corresponding Author: Meenu Agarwal, National DirectorClinical Board, Department of Endoscopy and ART, Morpheus IVF, Pune, Maharashtra, India, Phone: +919822036970 e-mail:drmjainagarwal@hotmail.com
}

scar because of curettage, myomectomy, metroplasty, hysteroscopy, and even manual removal of placenta. ${ }^{7-10}$ Imaging modalities, such as ultrasound with color Doppler and magnetic resonance imaging (MRI) are the mainstay for timely detection of such cases. Early intervention prevents severe complications, such as uterine rupture, hemorrhage, and hypovolemic shock.

Various treatment modalities include conservative management with intrasac or intralesional injection of MTX, ${ }^{11,12}$ potassium chloride ${ }^{13}$ hyperosmolar glucose, ${ }^{14}$ and crystalline trichosanthin. ${ }^{15}$ Systemic MTX treatment was found ideal for a CSP presenting before 8 weeks gestation with beta human chorionic gonadotropin (hCG) levels less than $12,000 \mathrm{mIU} / \mathrm{mL}^{16}$ Surgical modalities described are uterine curettage, ${ }^{2,17,18}$ resection of the abnormal area which showed appearances of trophoblastic tissue ${ }^{19}$ with laparoscopy, ${ }^{20,21}$ or laparotomy. ${ }^{22}$ Chao et al ${ }^{23}$ have described a successful hysteroscopic management of a CSP after failed curettage and MTX treatment. ${ }^{2}$

One study also compared the use of high-intensity focused ultrasound (HIFU) and uterine artery embolization for the management of CSP in which HIFU was found to be efficient, tolerable, and noninvasive. ${ }^{24}$

A 25-year-old lady, G3P2L2, presented with 3-month amenorrhea and continuous per vaginal (PV) bleeding for 1 month. The bleeding had increased since last 4 to 5 days. Her urine pregnancy test was positive. The obstetric history revealed that she was G3P2A0.

The first was a full-term normal vaginal delivery 3-year-old female child and the second was an emergency cesarean section (indication: fetal distress in second stage of labor) 7-month-old female child.

The detailed history of present pregnancy was as follows.

At 5.4 weeks of gestation, she had gone to her general physician for medical termination of pregnancy.

On pelvic ultrasound, a very small gestational sac was seen without fetal pole and yolk sac. Tablet mifepristone followed by misoprostol was given and the patient was asked to follow up after 2 weeks for a repeat ultrasound. She reported to her primary doctor after 10 days due to heavy bleeding requiring changing 5 to 6 pads per day.

A repeat ultrasound examination showed a single gestational sac measuring $11 \mathrm{~mm} \times 9 \mathrm{~mm}$ in the lower anterior segment at the site of previous lower segment 

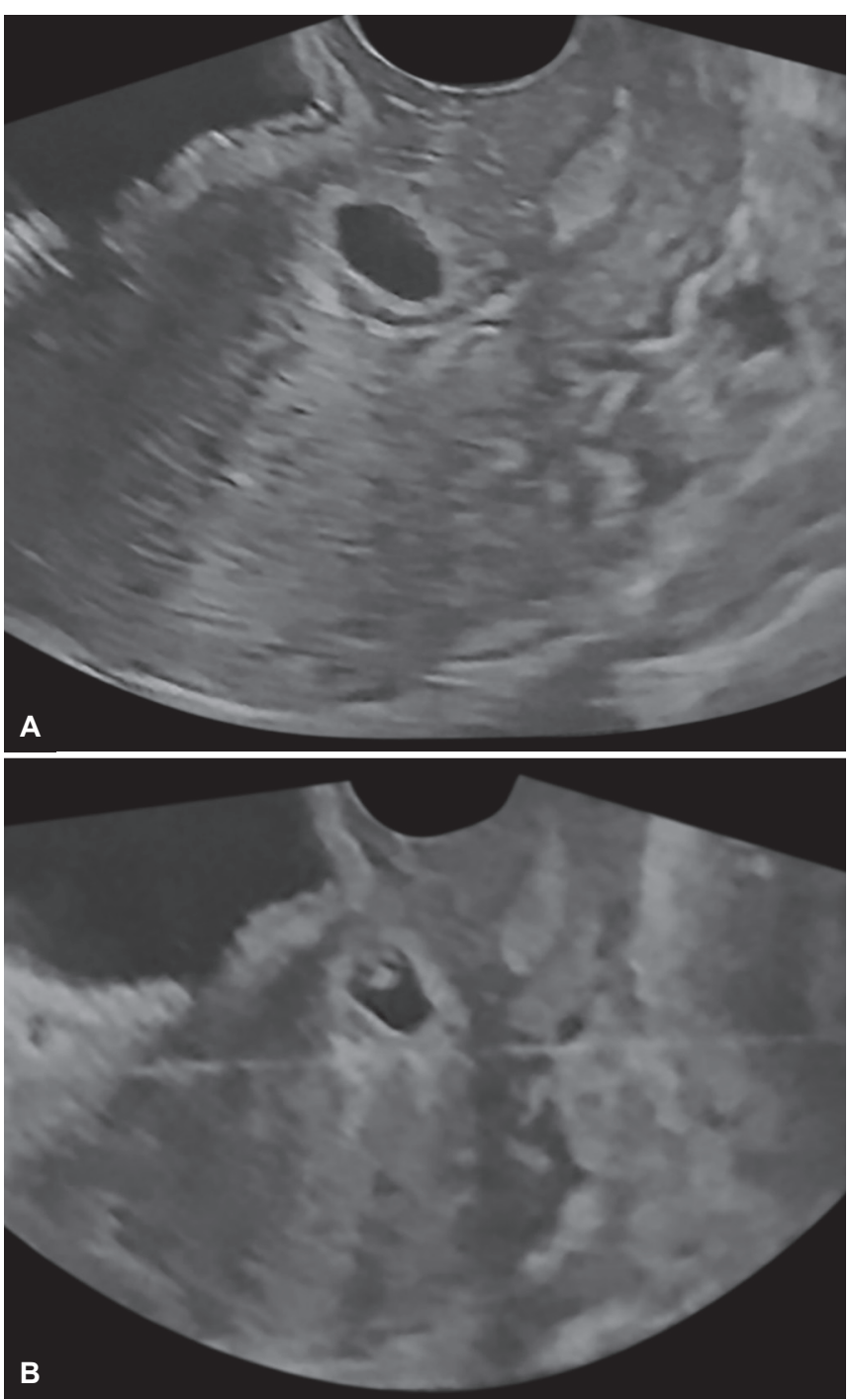

Figs 1A and B: A gestation sac of size $11 \mathrm{~mm} \times 9 \mathrm{~mm}$ at site of previous scar with live fetal pole of 6 weeks 1 day

cesarean section (LSCS) scar. Posterior sac margin was in contact with the endometrium. A fetal pole with crownrump length of 6 weeks 1 day with present cardiac activity was seen (Fig. 1). This was suggestive of a cesarean section scar ectopic pregnancy.

The beta-hCG levels were 11,550 mIU/mL. After discussing the various methods for management of CSP, patient and her relatives opted for medical management with MTX with their primary doctor. Hemogram, liver function tests, and renal function tests were done and beta-hCG was repeated, which showed an increase to 22,280 $\mathrm{mIU} / \mathrm{mL}$.

Injection of MTX $80 \mathrm{mg}$ was given intramuscularly and the patient was admitted for observation for 24 hours. The patient was discharged the next day after ultrasound showed absence of cardiac activity. Serial beta-hCG monitoring was done. Four days later, beta-hCG dropped to $5,870 \mathrm{mIU} / \mathrm{mL}$.

A week later, the beta-hCG value was $5,130 \mathrm{mIU} / \mathrm{mL}$ and did not show a sufficient decline, so an ultrasound

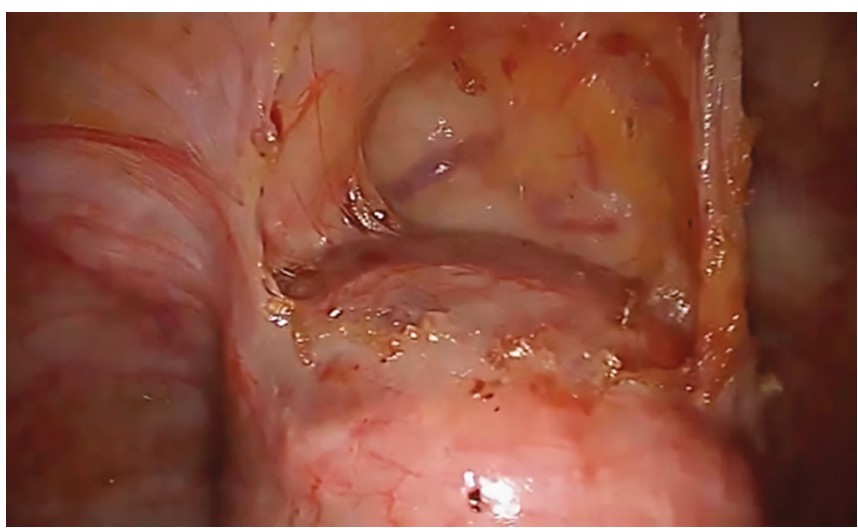

Fig. 2: Bladder peritoneum dissected and bladder base mobilized downward

was repeated which showed increase in the size of sac to $21 \times 10 \mathrm{~mm}$ with absence of cardiac activity. Weekly betahCG showed some decline thereafter till 4,290 mIU/mL and ultrasonography showed a persistent sac. Two weeks later, the sac size was $30 \times 21 \mathrm{~mm}$ with beta-hCG values of $3,520 \mathrm{mIU} / \mathrm{mL}$.

As the medical management was not successful, she was referred to us for laparoscopic management of scar ectopic pregnancy. The patient had refused exploratory laparotomy offered to her by her previous treating doctor. The patient was hemodynamically stable when she came to us. However, she was pale and tachycardia was noted. Decision for emergency laparoscopic excision of scar ectopic pregnancy was taken.

Patient was also explained about the need for SOSlaparotomy, and consent for SOS hysterectomy in untoward event of intractable bleeding during surgery was also taken. Two units of whole blood were cross-matched and reserved. On laparoscopy, a bulge was seen in the lower segment at the site of previous LSCS scar. Bladder peritoneum was dissected and bladder base was mobilized downward carefully to expose the cervicovesical fascia and the lower margin of cervix (Fig. 2).

Then the cervicovesical fascia was mobilized sufficiently down so as to visualize the thin bluish tinge of the sac seen through the isthmus (Fig. 3). The incision was taken over the sac with the active blade of harmonic.

Amniotic fluid was drained out by suction, and the sac was removed (Fig. 4). It was ensured that all the products of conception were removed and it was sent for histopathological examination.

The sac margins were dissected and after ensuring hemostasis, the incision was closed with deep interrupted sutures with vicryl (polyglactin) no 1 suture. The peritoneum was also closed with continuous sutures (Fig. 5).

The patient was hemodynamically stable postoperatively and was discharged the next day and she was advised to avoid conception for the next 6 months. The 


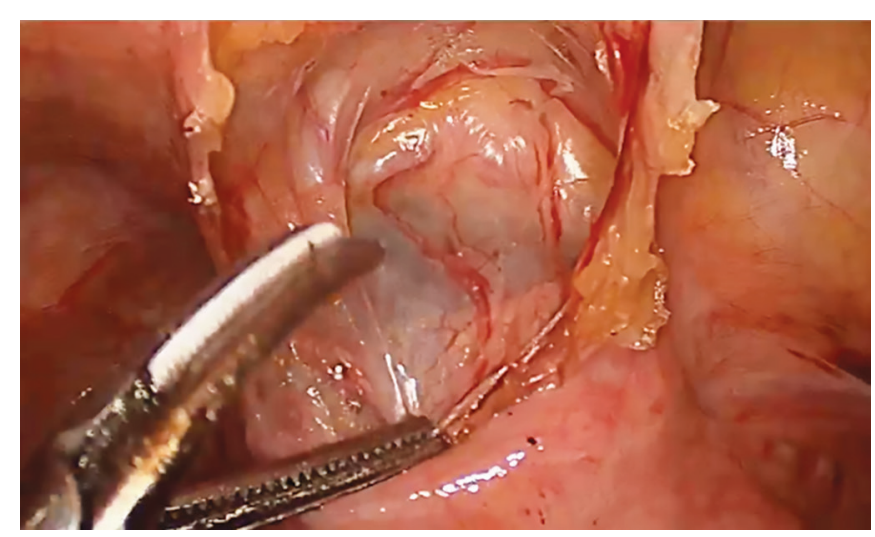

Fig. 3: Cervicovesical fascia mobilized further to expose the sac through the isthmus

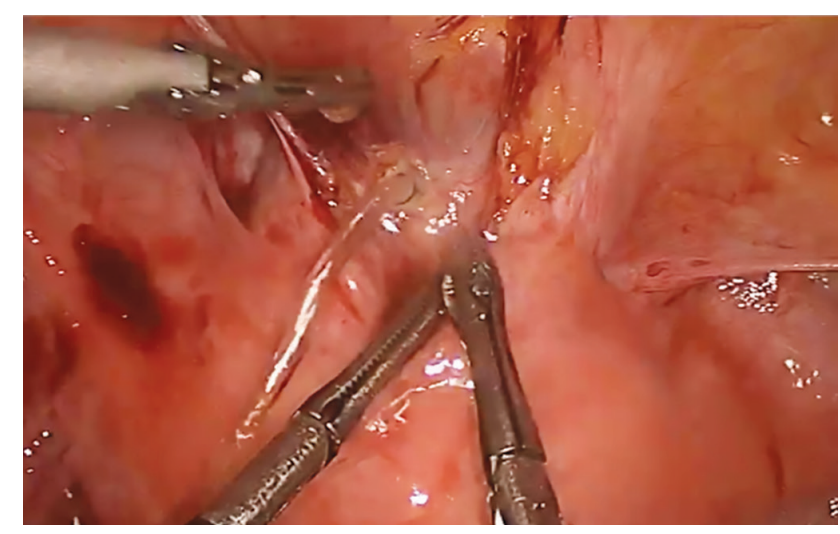

Fig. 4: Nick given with the active blade of harmonic and sac fluid spurting out
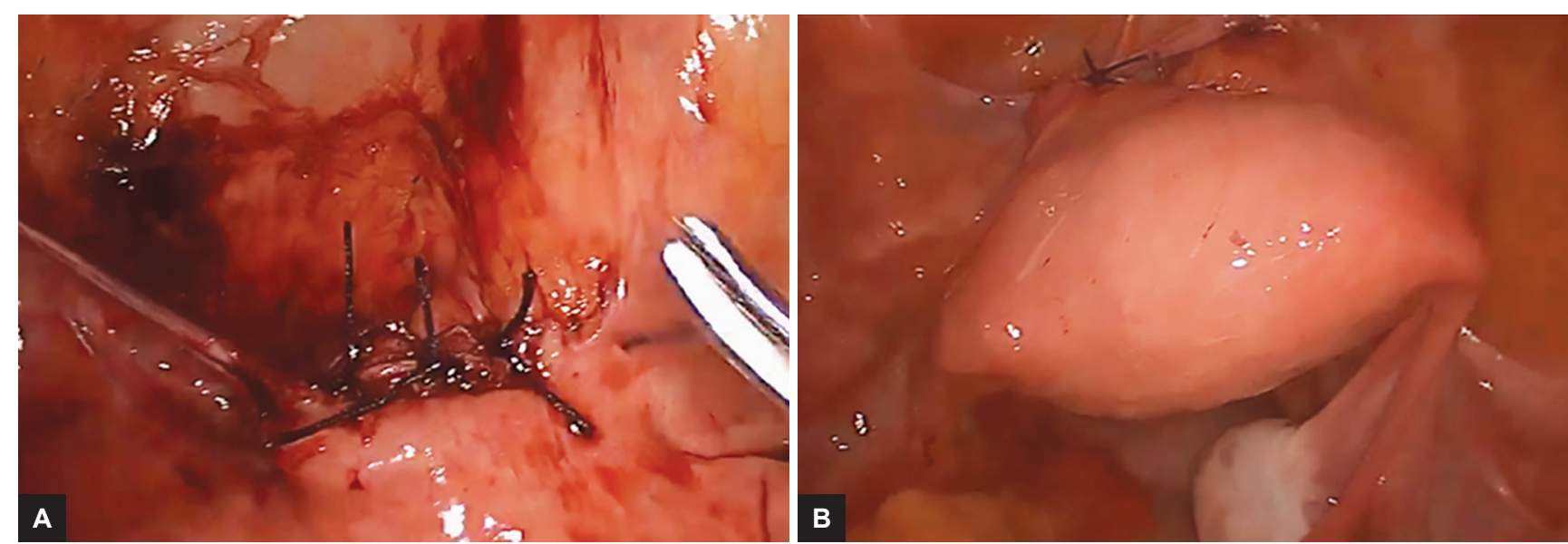

Figs 5A and B: Uterine defect closed with interrupted sutures and peritoneum closed with single-layer continuous sutures

histopathological examination report confirmed the presence of products of conception with some myometrial tissues.

\section{DISCUSSION}

Cesarean scar pregnancy is defined as an implantation of pregnancy in a fibrous tissue scar of a previous cesarean section. It is considered as one of the rarest forms of ectopic pregnancy and can be life threatening. ${ }^{1}$ Due to increase in the cesarean section rates for both maternal and fetal indications, the incidence of CSP is also steadily rising.

In this case, the patient had delivered by a cesarean section 7 months ago. The most probable mechanism that can explain scar implantation is that there is invasion of the myometrium through a microtubular tract between the cesarean section scar and the endometrial canal. ${ }^{2}$

The diagnosis of CSP requires a high vigilance as in most cases the clinical presentation poses a diagnostic dilemma.

This case was misdiagnosed as very early intrauterine pregnancy and medical termination of pregnancy was done. Persistence of sac after 10 days with cardiac activity at the site of previous cesarean scar and empty endometrial cavity and cervical canal with persistence of heavy painless vaginal bleeding established the diagnosis. Ultrasound with color Doppler should be the mainstay for the diagnosis of CSP.

The MRI may also prove helpful in establishing diagnosis. Sonographic criteria include an empty uterus, empty cervical canal, development of the gestational sac in the anterior part of the lower uterine segment or uterine isthmus, and an absence of healthy myometrium or presence of thinned out myometrium between the bladder wall and the gestational sac. ${ }^{2,7}$

Conservative management with intramuscular MTX was given. But persistence and increase in the size of sac and continued PV bleeding despite rapidly falling betahCG values after MTX therapy prompted a laparoscopic management of the CSP. Systemic MTX is ideal for CSP before 8 weeks and beta-hCG levels below 12,000 $\mathrm{mIU} / \mathrm{mL}$.

This case, although was ideal for MTX, a possibility of failure of medical treatment should always be counseled to the patient to prevent emotional frustration of an eventual surgical management. Laparoscopic wedge resection of scar ectopic is a very safe option for CSP, 
as resuturing of the defect prevents scar disruption in subsequent pregnancies.

Blood loss in laparoscopy can be further reduced with injection of vasopressin locally in the sac. An exploratory laparotomy is justified only in patients who have not responded to other treatment options, or in suspicion of uterine rupture, or nonavailability of laparoscopic expertise.

\section{CONCLUSION}

With the increasing incidence of cesarean section rates worldwide, the diagnosis of CSP should be an important differential diagnosis in patients presenting with painless PV bleeding with history of previous cesarean section in recent past. Proper use of imaging modalities will help in timely diagnosis and prevent catastrophic clinical scenarios.

All the treatment options should be thoroughly discussed with the patient and decision should be taken pertaining to patient's condition and wish. Laparoscopic management is a safe option. It needs standardization and can be the treatment of choice in selected group of patients. It would not only treat the present pathology but also treat the scar fistula for subsequent pregnancies.

\section{REFERENCES}

1. Maymon R, Halperin R, Mendlovic S, Schneider D, Herman A. Ectopic pregnancies in a Caesarean scar: review of the medical approach to an iatrogenic complication. Hum Reprod Update 2004 Nov-Dec;10(6):515-523.

2. Ash A, Smith A, Maxwell D. Caesarean scar pregnancy. BJOG 2007 Mar;114(3):253-263.

3. Jurkovic D, Hillaby K, Woelfer B, Lawrence A, Salim R, Elson CJ. First trimester diagnosis and management of pregnancies implanted into the lower uterine segment cesarean section scar. Ultrasound Obstet Gynecol 2003 Mar;21(3):220-227.

4. Seow KM, Huang LW, Lin YH, Lin MY, Tsai YL, Hwang JL. Cesarean scar pregnancy: issues in management. Ultrasound Obstet Gynecol 2004 Mar;23(3):247-253.

5. Michener C, Dickinson JE. Caesarean scar ectopic pregnancy: a single centre case series. Aust N Z J Obstet Gynaecol 2009 Oct;49(5):451-455.

6. Nukaga S, Aoki S, Kurusawa K, Takahashi T, Hirahara F. A case of misdiagnosed cesarean scar pregnancy with a viable birth at 28 weeks. Case Rep Obstet Gynecol 2014 Oct;2014:375685.

7. Nankali A, Ataee M, Shahlazadeh H, Daeichin S. Surgical management of CSEP: a case report. Case Rep Obstet Gynecol 2013 Nov;2013:525187.

8. Fylstra DL. Ectopic pregnancy within a cesarean scar: a review. Obstet Gynecol Surv 2002 Aug;57(8):537-543.
9. Godin PA, Bassil S, Donnez J. An ectopic pregnancy developing in a previous caesarean section scar. Fertil Steril 1997 Feb;67(2):398-400.

10. Fait G, Goyert G, Sundareson A, Pickens A Jr. Intramural pregnancy with fetal survival: case history and discussion of etiologic factors. Obstet Gynecol 1987 Sep;70(3 Pt 2):472-474.

11. Ravhon A, Ben-Chetrit A, Rabinowitz R, Neuman M, Beller U. Successful methotrexate treatment of a viable pregnancy within a thin uterine scar. Br J Obstet Gynaecol 1997 May; 104(5):628-629.

12. Lai YM, Lee JD, Lee CL, Chen TC, Soong YK. An ectopic pregnancy embedded in the myometrium of a previous cesarean section scar. Acta Obstet Gynecol Scand 1995 Aug; 74(7):573-576.

13. Hartung J, Meckies J. Management of a case of uterine scar pregnancy by transabdominal potassium chloride injection. Ultrasound Obstet Gynecol 2003 Jan;21(1):94-95.

14. Roberts H, Kohlenber C, Lanzarone V, Murray H. Ectopic pregnancy in lower segment uterine scar. Aust N Z J Obstet Gynaecol 1998 Feb;38(1):114-116.

15. Weimin $\mathrm{W}$, Wenqing L. Effect of early pregnancy on a previous lower segment cesarean section scar. Int J Gynecol Obstet 2002 Jun;77(3):201-207.

16. Bodur S, Özdamar Ö, Kılıç S, Gün I. The efficacy of the systemic methotrexate treatment in caesarean scar ectopic pregnancy: a quantitative review of English literature. J Obstet Gynaecol 2015 Apr;35(3):290-296.

17. Arslan M, Pata O, Dilek TU, Aktas A, Aban M, Dilek S. Treatment of viable cesarean scar ectopic pregnancy with suction curettage. Int J Gynec1ol Obstet 2005 May;89(2):163-166.

18. Wang CB, Tseng CJ. Primary evacuation therapy for cesarean scar pregnancy: three new cases and review. Ultrasound Obstet Gynecol 2006 Feb;27(2):222-226.

19. Deb S, Clewes J, Hewer C, Raine-Fenning N. The management of Cesarean scar ectopic pregnancy following treatment with methotrexate-a clinical challenge. Ultrasound Obstet Gynecol 2007 Nov;30(6):889-892

20. Wang CJ, Chao AS, Yuen LT, Wang CW, Soong YK, Lee CL. Endoscopic management of cesarean scar pregnancy. Fertil Steril 2006 Feb;85(2):494-497.

21. Wang YL, Su TH, Chen HS. Operative laparoscopy for unruptured ectopic pregnancy in a caesarean scar. BJOG 2006 Sep;113(9):1035-1038.

22. Vial $Y$, Petignat $P$, Hohlfeld P. Pregnancy in a cesarean scar. Ultrasound Obstet Gynecol 2000 Nov;16(6):592-593.

23. Chao A, Wang TH, Wang CJ, Lee CL, Chao AS. Hysteroscopic management of cesarean scar pregnancy after unsuccessful methotrexate treatment. J Minim Invasive Gynecol 2005 JulAug;12(4):374-376.

24. Xiao J, Shi Z, Zhou J, Zhu J, Zhou X, Wang F, Zhang S. Cesarean scar pregnancy: comparing the efficacy and tolerability of treatment with high-intensity focused ultrasound and uterine artery embolization. Ultrasound Med Biol 2017 Mar;43(3):640-647. 